WellBeing International

WBI Studies Repository

8-1975

\title{
The Effect of Straw on the Behaviour of Sows in Tether Stalls
}

D. Fraser

University of Edinburgh, dfraser@mail.ubc.ca

Follow this and additional works at: https://www.wellbeingintlstudiesrepository.org/houcfani

Part of the Agribusiness Commons, Animal Studies Commons, and the Operations and Supply Chain Management Commons

\section{Recommended Citation}

Fraser, D. (1975). The effect of straw on the behaviour of sows in tether stalls. Animal production, 21(01), 59-68.

This material is brought to you for free and open access by WellBeing International. It has been accepted for inclusion by an authorized administrator of the WBI Studies Repository. For more information, please contact wbisr-info@wellbeingintl.org.

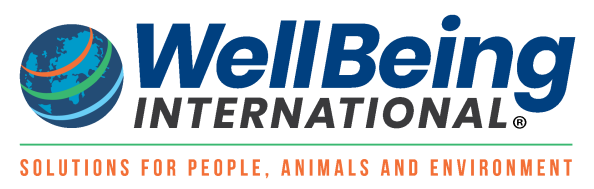




\title{
The Effect of Straw on the Behaviour of Sows in Tether Stalls
}

\author{
D. Fraser \\ University of Edinburgh
}

\begin{abstract}
The behaviour of sows in tether stalls with and without straw was studied in two experiments. Sows lay down more when $1 \mathrm{~kg}$ of straw was provided daily, especially when it was chopped and mixed wet with the food (dietary effect). Sows without straw performed a variety of stereotyped oral and other activities which were greatly reduced by the provision of loose straw that could be chewed and manipulated throughout the day (recreational effect). Sows were frequently seen standing or sitting motionless with the head drooping, probably in a state of drowsiness. This behaviour was virtually eliminated by full straw bedding (bedding effect). Certain 'comfort movements', bar-biting at feeding time, and biting the neighbouring sows, were not influenced by straw. It is concluded that the dietary, recreational and bedding aspects of straw are all significant, but influence different aspects of the animals' behaviour. The significance of bar-biting and other activities is discussed.
\end{abstract}

\section{INTRODUCTION}

The housing of sows in small individual stalls on bare concrete floors is one of the most controversial of modern husbandry practices, not least because many animals kept in this way show behaviour which is thought to be abnormal. Such behaviour, if properly understood, might provide insight into an animal's degree of success in adapting to a husbandry system (Thorpe, 1965, 1969; Loew, 1972; Wood-Gush, 1973). In the case of sow stalls, however, the problem is made complex by the many features of the system which could conceivably lead to abnormal behaviour. These include restraint of movement, the close proximity of many other sows, a barren physical environment which affords little opportunity for exploratory or manipulatory activities, and the fact that the animals are normally obliged to lie on a solid, unbedded surface. In addition sows kept in this way are usually fed only once a day on a concentrated diet, providing far less bulk than would fill the gut and less energy than the animals would take if fed ad libitum.

The present study was suggested by the incidental observation that if sows in stalls are provided with straw bedding, they appear more 'placid', showing less bar-biting and other possibly abnormal behaviour (R. Harrison, personal communication). If this is so, then an analysis of how straw affects such activities might provide some clues as to their cause and significance, thus improving an observer's ability to diagnose specific environmental deficiencies on the basis of behaviour. Furthermore, from the viewpoint of animal welfare it would be of interest to know to what extent the mere provision of straw can reduce abnormal behaviour by sows in stalls, This issue is made the more interesting by the finding of Hojgaard- 
Olsen and Nielsen (1966) that the offspring of sows with access to straw during gestation and lactation were heavier at birth and at weaning.

In the first experiment reported below, animals were observed in a tether stall system with and without straw bedding. The main behavioural differences were further analysed in the second experiment by presenting straw in a variety of ways.

\section{EXPERIMENT 1}

\section{Method}

Twenty-four Large White $\times$ Landrace females (gilts) were studied in tether stalls over a 28-day period shortly before their first mating. They had been in the stalls without bedding for more than 1 month before the experiment began.

The stalls measured $0.7 \mathrm{~m}$ wide with side divisions $1.2 \mathrm{~m}$ long, and were arranged in two rows of 12 facing each other across a central passage $0.7 \mathrm{~m}$ wide. Accordingly all the gilts could see other animals in front, and could touch slightly the animals on either side through the divisions. The neck tethers consisted of steel and leather, and were attached to the divisions by a steel chain about $0.5 \mathrm{~m}$ long. The floor was solid concrete sloping slightly downward from the front of the stalls to the dung channel.

During the first 14 days of the experiment, the 12 gilts on one side of the room were bedded on straw while the others remained unbedded. The conditions were reversed in the second 14-day period. The animals were allowed to habituate to the experimental conditions during the first 9 days of each period, all behavioural observations being made during the last 5 days.

At the beginning of each 14-day period, the gilts to be bedded were each given 1.5 to $2.0 \mathrm{~kg}$ of loose straw in the food trough and underfoot. Each day dung and wet straw were removed, and the bedded animals were given an additional 0.5 to $1.0 \mathrm{~kg}$ of straw. The animals were given water and $2.0 \mathrm{~kg}$ of meal daily at $08.00 \mathrm{hr}$. Cleaning and re-strawing was done at 09.00 to $10.00 \mathrm{hr}$, and extra water was given at about $16.00 \mathrm{hr}$. The diet comprised $55.0 \%$ barley, $21.0 \%$ bruised oats, $15.5 \%$ maize, $2.5 \%$ fish meal, $5.0 \%$ molasses, $0.8 \%$ limestone, and $0.2 \%$ mineral/vitamin supplement. It contained $85.0 \%$ dry matter with a calculated chemical composition of $13.0 \%$ crude protein, $5.9 \%$ crude fibre, $2.8 \%$ ether extractives, $4.7 \%$ ash, and $73.6 \%$ nitrogen-free extractives. The digestible energy was calculated to be $14.7 \mathrm{MJ} / \mathrm{kg}$ dry matter.

Three types of observations were made. First the animals were studied closely for 15 min some time between 12.00 and $14.00 \mathrm{hr}$ on each of the 5 observation days in each experimental period. Three bedded and three unbedded animals were observed together in each 15-min session, with the observer watching from a distance of 1 to $3 \mathrm{~m}$. A stop-clock was used to indicate 1-min intervals, and a written record was made of the number of minutes in which each pig performed the various categories of behaviour listed in Table 1. Two of these activities were noticed early in the experiment and were scored thereafter. One consisted of the animal standing or sitting motionless, often for tens of seconds at a time, usually with the head drooping and with the eyes half closed or glassy-looking. In the other activity the animals stood with the snout and face pushed forward between the bars of the stall, often holding this posture for up to a minute or more without engaging in other behaviour.

The second set of observations involved a 2-hr time-sampling study during the afternoons of each of the 5 observation days of both experimental periods. Throughout the $2 \mathrm{hr}$, the experimenter looked quietly into the room every $5 \mathrm{~min}$ and noted whether each animal was standing, sitting or lying. 
Thirdly, the animals were observed on 15 occasions during the 5 min before being given food or water. A record was made of the frequency with which each animal bit the front bars of the stall. When a pig bit the bars a number of times in rapid succession the series was scored only once if it lasted less than $5 \mathrm{sec}$, or twice if it was longer than $5 \mathrm{sec}$.

\section{Results}

Table 1 summarizes the behavioural differences observed with and without straw bedding during the ten 15-min periods of close observation. Levels of statistical significance are based on the Wilcoxon matched-pairs signed-ranks test (Siegel, 1956).

TABLE 1

Experiment 1. The mean score for 14 behavioural categories during the five daily 15-min periods of observation (maximum score is 75)

\begin{tabular}{|c|c|c|c|c|c|}
\hline \multirow[t]{2}{*}{ Behaviour } & \multicolumn{2}{|c|}{ With straw } & \multicolumn{2}{|c|}{ Without straw } & \multirow{2}{*}{$\begin{array}{l}\text { Significance } \\
\text { of difference* }\end{array}$} \\
\hline & Mean & SE & Mean & SE & \\
\hline \multicolumn{6}{|l|}{ Posture } \\
\hline Lie & $42 \cdot 7$ & $3 \cdot 2$ & $36 \cdot 0$ & $5 \cdot 0$ & $<0.05$ \\
\hline Stand & $33 \cdot 1$ & $3 \cdot 2$ & $40 \cdot 3$ & $4 \cdot 8$ & $<0.05$ \\
\hline Sit & $1 \cdot 6$ & 0.8 & 1.5 & $1 \cdot 1$ & NS. \\
\hline Stand or sit motionless & $0 \cdot 1$ & $0 \cdot 1$ & $3 \cdot 8$ & $1 \cdot 8$ & $<0.01$ \\
\hline Stand or sit with head pushed through bars & 0.6 & $0 \cdot 1$ & $1 \cdot 7$ & 0.5 & $<0.01$ \\
\hline \multicolumn{6}{|l|}{ Comfort movements } \\
\hline Rub body on walls & $3 \cdot 6$ & 0.7 & $5 \cdot 0$ & 0.9 & NS \\
\hline Scratch with hind leg & $2 \cdot 3$ & 0.7 & 2.9 & 0.7 & NS \\
\hline Shake head & $1 \cdot 0$ & 0.2 & $1 \cdot 3$ & 0.3 & NS \\
\hline \multicolumn{6}{|l|}{ Other activities } \\
\hline Chew and manipulate straw & $24 \cdot 5$ & $2 \cdot 8$ & 0 & & $<0.01$ \\
\hline Nose and lick bars, floor, trough and chain & $3 \cdot 5$ & 0.9 & $15 \cdot 9$ & $2 \cdot 3$ & $<0.01$ \\
\hline Bite bars, trough and chain & $3 \cdot 2$ & 0.9 & $8 \cdot 0$ & $2 \cdot 2$ & $<0.05$ \\
\hline Nose and lick neighbour & $1 \cdot 0$ & 0.3 & $3 \cdot 1$ & 0.9 & $<0.01$ \\
\hline Bite neighbour & $0 \cdot 2$ & $0 \cdot 2$ & $0 \cdot 1$ & $0 \cdot 1$ & NS \\
\hline Bite, nose and lick neighbour's tether & 0.8 & 0.4 & 1.9 & 0.7 & $<0.05$ \\
\hline
\end{tabular}

* In this and the following Tables statistical comparisons are made by the Wilcoxon matched-pairs signed-ranks test.

TABLE 2

Experiment 2. The mean percentage score for lying, standing and sitting, and the mean frequency of changing position, during the daily 2-hr time-sampling periods

\begin{tabular}{|lccccccc|}
\hline Behaviour & \multicolumn{2}{c}{ With straw } & & \multicolumn{2}{c|}{ Without straw } & \multicolumn{2}{c}{$\begin{array}{c}\text { Significance } \\
\text { of difference }\end{array}$} \\
\cline { 2 - 3 } \cline { 6 - 8 } & Mean & SE & & Mean & SE & & $<0.05$ \\
Lie (percentage score) & 70.5 & 2.7 & & 65.0 & 3.7 & NS \\
Stand (percentage score) & 28.2 & 2.8 & & 32.8 & 3.5 & $<0.01$ \\
Sit (percentage score) & 0.8 & 0.4 & & 1.7 & 0.6 & NS \\
Frequency of changing & 2.6 & 0.2 & & 2.6 & 0.2 & \\
\hline
\end{tabular}


Table 2 shows the mean percentage time, based on the ten 2-hr periods of the time-sampling study, spent lying, standing and sitting, and the mean number of occasions (per 2-hr period) on which an animal changed from lying to standing or vice versa between one observation and the next.

The 15 observations during feeding and watering revealed large differences among animals in the frequency of bar-biting, with total scores ranging from 0 to 155 . The mean scores ( $\pm \mathrm{SE}$ ) for bar-biting were $11 \cdot 7 \pm 6 \cdot 1$ with straw and $11 \cdot 2 \pm 6 \cdot 1$ without.

\section{EXPERIMENT 2}

In the first experiment straw apparently influenced the behaviour of the animals in a number of ways, but there is little indication of how it exerted these effects. The straw was the target of much oral and manipulatory activity by the animals; it presumably rendered the lying surface more comfortable; and the portion ingested may have helped to fill the gut, thus compensating for the lack of bulk in the concentrated diet provided. The following experiment attempted to separate the dietary, recreational and bedding aspects by providing straw in three ways: (1) chopped straw mixed with the food, to be eaten but not available for play or bedding; (2) loose straw in the food trough for recreational purposes, but in insufficient quantity for bedding; and (3) a large amount of loose straw both in the trough and underfoot.

\section{Method}

Twenty Large White or Large White $\times$ Landrace adult females (sows) were studied during a second or subsequent pregnancy. The animals were housed in a single row of tether stalls with dimensions and fixings similar to those used in Experiment 1. The sows normally stood on an area of solid concrete $1.1 \mathrm{~m}$ long, with a slatted area behind. During the experiment the slatted part was covered with flat sheets of asbestos cement to prevent the bedding from falling through the openings.

There were four experimental treatments:

F. (Full bedding)--Each sow received $3.0 \mathrm{~kg}$ of loose straw every day, with about $1 \mathrm{~kg}$ placed in the food trough and the remainder under foot.

T. (Trough)--Sows received 0.8 to $1.0 \mathrm{~kg}$ of loose straw daily in the food trough.

C. (Chopped)--Each sow received 0.8 to $1.0 \mathrm{~kg}$ of chopped straw wetted and mixed carefully with the daily ration of food. Most of the pieces of chopped straw were 30 to $60 \mathrm{~mm}$ in length.

N. (No straw)--The animals received no straw.

The experiment consisted of four consecutive 10-day periods. The 20 sows were regarded as four groups, each consisting of five adjacent animals. Each group of five sows was assigned to one of the four treatments during each period as determined by a $4 \times 4$ Latin square.

The precise quantity of straw given each day in treatments $C$ and $T$ was adjusted on the basis of the speed with which the animals ate the straw on the previous day. It was intended that in treatment $C$ the sows would eat all the straw with the food, and have none left when observations began, while in treatment $\mathrm{T}$, some straw would remain throughout the observations. In order that these treatments would be comparable, however, the same amount of straw was given to all the sows in these two treatments on any given day.

Every day the animals were given $2.0 \mathrm{~kg}$ of pelleted dry sow ration of the same composition as used in Experiment 1 (mixed with moistened chopped straw in treatment C) at $10.00 \mathrm{hr}$. Dung and straw from the 
previous day were then removed, and the fresh loose straw was given. Water, dispensed by individual nipple drinkers, was available for about $2 \mathrm{hr}$ during this time, and again for a brief period in the evening.

The first 5 days of each period were allowed for the sows to habituate to the experimental treatments. On each of the remaining 5 days they were observed during two 80-min watches, the first beginning about $13.00 \mathrm{hr}$ and the second about $16.00 \mathrm{hr}$. In each watch behaviour was recorded for group 1 for $1 \mathrm{~min}$, then group 2 for $1 \mathrm{~min}$, then similarly for group 3 and 4, and then the series was repeated until each group had been observed during 20 min in total: When recording behaviour, the observer stood about 3 min front of the animals and separated from them by a feeding passage and another row of tethered sows.

As in Experiment 1 each animal was scored as having performed or not performed each behavioural category during each minute of observation. Licking and nosing the surroundings was scored only once for any animal in any one minute, but the part of the surroundings (bars, trough, floor or chain) that was nosed first in the minute was recorded. Also, a sow was not scored for licking and nosing the bars, chain or trough if it had been scored for biting that part of the surroundings in the same minute. This was done because animals almost always licked or nosed a part of the environment in the course of biting it.

In addition to the behavioural categories of Experiment 1, three others were used. 'Head waving' consisted of a sow repeatedly waving its head from side to side in a vigorous, stereotyped manner. A sow was scored for 'chewing movements' when it moved its jaws as if chewing, but without any obvious object in the mouth. 'Stretching the mouth' was scored when a sow repeatedly opened and closed its mouth in an exaggerated way, each time holding the mouth open longer than in normal mastication.

On all five observation days of each period, $200-300 \mathrm{~g}$ of faeces were collected from behind each sow. The five daily samples were frozen, pooled for each animal, and analysed for crude fibre by the method of Whitehouse, Zarow and Shay (1945).

TABLE 3

Experiment 2. The mean score ( $\pm S E)$ for the four postures and the three most common activities under the four experimental treatments

\begin{tabular}{|c|c|c|c|c|c|c|c|c|c|}
\hline \multirow{3}{*}{ Behaviour } & \multicolumn{8}{|c|}{ Experimental treatment } & \multirow{3}{*}{$\begin{array}{l}\text { Statistical } \\
\text { comparison }\end{array}$} \\
\hline & \multicolumn{2}{|c|}{ Full (F) } & \multicolumn{2}{|c|}{ Trough (T) } & \multicolumn{2}{|c|}{ Chopped (C) } & \multicolumn{2}{|c|}{ No straw (N) } & \\
\hline & Mean & SE & Mean & SE & Mean & SE & Mean & SE & \\
\hline \multicolumn{10}{|l|}{ Posture } \\
\hline Lie & $74 \cdot 8$ & 8.9 & $74 \cdot 2$ & $10 \cdot 5$ & $84 \cdot 6$ & $11 \cdot 4$ & $46 \cdot 2$ & $10 \cdot 2$ & $\begin{array}{l}\mathrm{C}>\mathrm{N}^{* *} \\
\mathrm{~F}, \mathrm{~T}>\mathrm{N}^{*}\end{array}$ \\
\hline Stand & $125 \cdot 3$ & $8 \cdot 7$ & $125 \cdot 0$ & $10 \cdot 8$ & $105 \cdot 5$ & $12 \cdot 8$ & $144 \cdot 2$ & $10 \cdot 5$ & $\begin{array}{l}C<N^{\star *} \\
C<T^{\star}\end{array}$ \\
\hline Sit & $2 \cdot 2$ & $1 \cdot 0$ & $4 \cdot 6$ & 1.9 & $14 \cdot 1$ & $8 \cdot 0$ & $12 \cdot 3$ & $8 \cdot 7$ & $\mathrm{~F}<\mathrm{C}^{*}$ \\
\hline Stand or sit motionless & $1 \cdot 8$ & $1 \cdot 0$ & $18 \cdot 0$ & $7 \cdot 4$ & $38 \cdot 2$ & $14 \cdot 1$ & $35 \cdot 3$ & $12 \cdot 2$ & $\begin{array}{l}\mathrm{F}<\mathrm{T}, \mathrm{C}, \mathrm{N}^{\star *} \\
\mathrm{~T}<\mathrm{C}, \mathrm{N}^{*}\end{array}$ \\
\hline \multicolumn{10}{|c|}{ Main activities (as percentage of time spent standing) } \\
\hline Chew and manipulate straw & $92 \cdot 1$ & $2 \cdot 5$ & $61 \cdot 5$ & $5 \cdot 6$ & $13 \cdot 1$ & $3 \cdot 1$ & $1 \cdot 8$ & $1 \cdot 0$ & $\mathrm{~F}>\mathrm{T}>\mathrm{C}>\mathrm{N}^{\star *}$ \\
\hline $\begin{array}{l}\text { Nose and lick bars, floor, } \\
\text { trough and chain }\end{array}$ & $3 \cdot 2$ & $1 \cdot 8$ & $10 \cdot 7$ & $3 \cdot 2$ & $33 \cdot 6$ & $6 \cdot 4$ & $30 \cdot 7$ & $6 \cdot 1$ & $\mathrm{~F}<\mathrm{T}<\mathrm{C}, \mathrm{N}^{\star *}$ \\
\hline Bite bars, trough and chain & $5 \cdot 0$ & $2 \cdot 1$ & $11 \cdot 3$ & $3 \cdot 2$ & $37 \cdot 2$ & $7 \cdot 6$ & $42 \cdot 5$ & $8 \cdot 0$ & $\mathrm{~F}<\mathrm{T}<\mathrm{C}, \mathrm{N}^{\star \star}$ \\
\hline
\end{tabular}




\section{Results}

With treatment $C$ the sows had eaten all or nearly all of the chopped straw by the beginning of the first watch in $77 \%$ of cases, and by the beginning of the second watch in $85 \%$ of cases. With treatment $T$ there was little or no loose straw remaining in $24 \%$ of cases at the beginning of the first watch, and in $55 \%$ of cases at the beginning of the second watch. Sows receiving treatment $F$ had considerable straw available throughout.

Over the experiment as a whole, chewing and manipulating straw was the most common single activity, occurring in $24.8 \%$ of the total minutes of observation. Biting the surroundings occurred in $13.8 \%$, nosing and licking the surroundings in $11.1 \%$, and the other activities in less than $5 \%$ of the total minutes of observation. Biting the bars of the stalls accounted for $99 \%$ of instances of biting the surroundings. Nosing and licking the bars accounted for $54 \%$ of instances of nosing and licking the surroundings, the remainder being directed at the floor (22\%), the chain (14\%), and the trough (10\%). With full bedding, some activity involving the mouth or snout occurred in $99 \%$ of the minutes in which a sow stood, excluding minutes in which she was specifically scored as standing or sitting motionless. The comparable percentages were $93 \%$ with straw in the trough, $92 \%$ with no straw, and $90 \%$ with chopped straw in the diet.

Table 3 shows the scores for the four postures and for the three most common activities. Since these three activities normally occurred only when the sows were standing, the scores are expressed as a percentage of the score for standing in each treatment. The scores for eight less common activities are summarized in Table 4.

Two sows were removed during the experiment because of lameness. This made Latin square analysis of variance difficult. Accordingly the treatments were compared by the Wilcoxon matched-pairs signed-ranks test as summarized in Tables 3 and 4.

TABLE 4

Experiment 2. The mean score ( \pm SE) for eight activities under the four experimental treatments

\begin{tabular}{|c|c|c|c|c|c|c|c|c|c|}
\hline \multirow{3}{*}{ Behaviour } & \multicolumn{8}{|c|}{ Experimental treatment } & \multirow{3}{*}{$\begin{array}{l}\text { Statistical } \\
\text { comparison }\end{array}$} \\
\hline & \multicolumn{2}{|c|}{ Full (F) } & \multicolumn{2}{|c|}{ Trough (T) } & \multicolumn{2}{|c|}{ Chopped (C) } & \multicolumn{2}{|c|}{ No straw $(\mathrm{N})$} & \\
\hline & Mean & SE & Mean & SE & Mean & SE & Mean & $\mathrm{SE}$ & \\
\hline Rub on walls & $2 \cdot 4$ & 0.7 & 2.5 & 0.7 & $2 \cdot 9$ & 0.8 & $2 \cdot 3$ & 0.5 & $\begin{array}{l}---- \\
\end{array}$ \\
\hline Scratch with hind leg & $1 \cdot 3$ & 0.5 & 1.0 & 0.3 & $1 \cdot 2$ & 0.4 & $1 \cdot 2$ & 0.5 & ----- \\
\hline Head shake & $2 \cdot 4$ & 0.8 & $4 \cdot 5$ & $1 \cdot 2$ & $4 \cdot 4$ & $1 \cdot 3$ & $4 \cdot 4$ & 1.4 & ----- \\
\hline Nose and lick neighbour & $0 \cdot 1$ & $0 \cdot 1$ & 0.5 & 0.3 & $1 \cdot 0$ & 0.5 & $1 \cdot 7$ & 0.6 & $\begin{array}{l}F<N^{* *} \\
F<C^{*} T<N^{*}\end{array}$ \\
\hline Bite neighbour & $1 \cdot 3$ & 0.5 & $1 \cdot 2$ & 0.3 & 1.0 & 0.3 & $1 \cdot 2$ & 0.5 & \\
\hline Head wave & 0.9 & 0.4 & $6 \cdot 1$ & $4 \cdot 3$ & $11 \cdot 1$ & $5 \cdot 7$ & $20 \cdot 8$ & $10 \cdot 0$ & $\begin{array}{l}\mathrm{F}, \mathrm{T}<\mathrm{N}^{\star *} \\
\mathrm{~T}<\mathrm{C}^{*}\end{array}$ \\
\hline Chew & 1.4 & $1 \cdot 2$ & $3 \cdot 8$ & $1 \cdot 5$ & $11 \cdot 9$ & $4 \cdot 3$ & $18 \cdot 9$ & $7 \cdot 0$ & $\begin{array}{l}F<T, C, N^{\star *} \\
T<N^{\star *}\end{array}$ \\
\hline Stretch mouth & 0 & & 1.7 & $1 \cdot 7$ & $3 \cdot 5$ & $2 \cdot 8$ & 3.5 & $2 \cdot 6$ & $\mathrm{~F}<\mathrm{N}^{*}$ \\
\hline
\end{tabular}

Since the supply of loose straw in treatment $T$ was exhausted in more than half the cases by the beginning of the second watch, the two watches were analysed separately. The chief difference was that less nosing, licking and biting the stall and fixtures occurred during the first watch (34\% of the total for the condition) than during the second. 
Certain activities were performed consistently more by some sows than by others throughout the experiment. Correlation coefficients were calculated relating each sow's score for particular categories under treatments $C$ and $N$ (since there were few differences between these treatments in the mean scores of the various activities). Coefficients of +0.8 or greater were found for sitting, biting the bars, nosing and licking the bars, head waving, mouth stretching and biting the neighbour. Coefficients were particularly low for rubbing on the walls and for scratching with a hind leg.

Three behavioural categories-sitting, standing or sitting motionless, and nosing the floor-were often performed by sows when they were about to lie down. In treatments $F$ and $T$ there was a steady increase in the incidence of sitting and of standing or sitting motionless during the four intervals before the animal lay down: sitting rose from a score of $2 \%$ to $7 \%$; and standing or sitting motionless rose from $9 \%$ to $22 \%$ over these four observations. In treatments $\mathrm{C}$ and $\mathrm{N}$, with no loose straw, both activities were consistently maintained at higher levels ( $8 \%$ to $10 \%$, and $31 \%$ to $39 \%$ respectively), and showed no increase in frequency before lying occurred. Nosing the floor was rarely observed in treatments $F$ and $T$, but it showed a sharp increase from $8 \%$ to $21 \%$ in the other two treatments during the two intervals before an animal lay down.

Many sows performed bar-biting just before urinating or defaecating. This activity was scored during the same minute as defaecation or urination in $47 \%$ of instances of these two categories. In contrast, barbiting occurred during only $19 \%$ of the total minutes in which a sow was scored as standing.

Defaecation was observed twice among animals given no straw and 9, 12 and 12 times among animals on treatments $\mathrm{C}, \mathrm{T}$ and $\mathrm{F}$, respectively. By contrast urination was scored 25 times in treatment $\mathrm{N}$, and 21 , 14 and 8 times in treatments $C, T$ and $F$ respectively. This finding is consistent with the experimenter's general impression that the sows without loose straw tended to toy with the nipple drinkers more during the morning period when water was available, and tended to be wetter underfoot.

The faeces samples from treatment $\mathrm{N}$ contained $25.7 \pm 0.8 \%$ crude fibre in the dry matter. In treatments $\mathrm{C}, \mathrm{T}$ and $\mathrm{F}$ the percentages were $31.3 \pm 0.6,31.3 \pm 0.5$ and $31.6 \pm 0.7$, respectively. Treatment $\mathrm{N}$ differed from all other treatments at the $0.1 \%$ level by Student's $t$ test for paired comparisons.

\section{DISCUSSION}

In Experiment 1 the bedded animals spent much time chewing and otherwise manipulating the straw, and had correspondingly lower scores for virtually all other oral or manipulatory activities. The main 'comfort movements' were not greatly affected, but the animals had lower scores both for standing or sitting motionless and for standing with the head pushed through the bars, when straw was provided. During the close observations the bedded gilts spent more time lying down; the time-sampling study during the afternoons revealed a less pronounced difference in the same direction, and a higher incidence of sitting among unbedded animals.

In Experiment 2 similar effects were observed when loose straw was presented in treatments $\mathrm{F}$ and $\mathrm{T}$. In addition, the different manners of presentation helped to separate the dietary, recreational and bedding aspects of straw. In treatments F, T and C, the animals appeared to eat similar amounts of straw (up to 1 $\mathrm{kg}$ daily), and had similar concentrations of fibre in the faeces. In treatment $\mathrm{C}$ the straw was largely eaten with the daily ration; in treatment $\mathrm{T}$ it was available to be explored and chewed after the ration had been eaten; and in treament $\mathrm{F}$, additional straw was provided to serve as bedding.

The sows spent more time lying down in all three treatments in which straw was provided, especially in treatment $C$ when it was given with the food. Since in this treatment the sows had eaten most of the straw before observations began, they presumably had more gut distension than in the other treatments. 
Standing or sitting motionless was almost eliminated by full bedding, and was reduced somewhat by the provision of a smaller amount of loose straw. This behaviour may represent a state of drowsiness. When loose straw was available, the activity typically occurred in a brief interval just before a sow lay down. In the absence of bedding, the floor surface may provide the animal with less incentive to lie; accordingly the behaviour persists for prolonged periods, with the animals apparently beginning to sleep while still standing. If this interpretation is correct, then a high incidence of standing or sitting motionless may indicate a lack of physical comfort. The category 'sitting' followed trends similar to those of standing or sitting motionless. An unusually high incidence of this activity might also indicate a reluctance to lie down.

Most of the simple repetitive acts, including the manipulatory activities of the mouth and snout, were greatly reduced by the provision of loose straw (treatments $F$ and $T$ ) but not by chopped straw in the diet (treatment $\mathrm{C}$ ). In most cases the reduction was more striking with full bedding than with loose straw in the trough, perhaps because the smaller amount of straw was often exhausted before the end of the observations. By way of interpreting such stereotyped activities, the results show that the sows engaged in some behaviour involving the mouth or snout during most of their active minutes. When loose straw was available, it was chewed and manipulated throughout most of this time, but when there was no straw, the animals performed a great variety of other oral activities, often of a stereotyped nature. Precisely which activities were performed depended partly on idiosyncratic differences between animals, and partly on the tendency of certain activities to occur in particular contexts.

The results suggest, therefore, that the dietary, recreational and bedding aspects of straw all influence the behaviour of the animals, but in different ways. The ingestion of straw increases the amount of time spent lying down; the availability of loose straw to be explored and chewed reduces the incidence of unusual or stereotyped activities especially of the mouth and snout; and the provision of bedding almost eliminates standing or sitting motionless in an apparent state of drowsiness.

The experiments indicate that bar-biting occurs in at least three distinct contexts: (i) when sows are disturbed, especially before feeding or watering; (ii) in a 'chronic' form throughout much of the day in the absence of any special disturbance; and (iii) just before defaecation or urination. The provision of straw exerted a clear influence on only the 'chronic' type of bar-biting.

The animals in Experiment I, particularly those without straw, frequently stood with the head pushed through the bars of the pen. This activity may be related to standing motionless. It was not observed as a distinct activity in Experiment 2, possibly because of the arrangement of the bars. Another difference between the two experiments is seen in the incidence of the three comfort movements. In Experiment 1 rubbing on the walls was the most common and head-shaking was the least; in Experiment 2 headshaking was the most common and scratching with a hind leg was the least. It would be of interest to know whether such changes merely reflect differences in age and environment, or whether they offer insight into some aspect of the animals' physical condition such as skin hygiene.

\section{ACKNOWLEDGEMENTS}

The author is grateful to Mr P. Fraser for kindly assisting with the experiments, to Dr P. Crooks for the chemical analysis, to Mr J. Fitzsimons, Dr D. G. Peers, Dr. W. J. M. Black and the pig unit staff for their cooperation. The work was supported by the Agricultural Research Council with the cooperation of Dr D. G. M. Wood-Gush and Professor F. W. H. Elsley. 


\section{REFERENCES}

HØJGAARD-OLSEN, N.J. and NIELSEN, H. E. 1966. Bedding for sows. Landøkon. aarbog, pp. 12-15. Nat. Res. Inst. of Animal Science, Copenhagen.

LOEW, F. M. 1972. The veterinarian and intensive livestock production: humane considerations. Can. vet. J. 13: 229-233.

SIEGEL, S. 1956. Non-parametric Statistics for the Behavioral Sciences. McGraw-Hill, New York.

THORPE, W. H. 1965. The assessment of pain and distress in animals. In Report of the Technical Committee to enquire into the Welfare of Animals kept under Intensive Livestock Husbandry Systems, pp. 71-79. F. W. R. Brambell, Chairman. Cmnd. 2836, Her Majesty's Stationery Office, London.

THORPE, W. H. 1969. Welfare of domestic animals. Nature, Lond. 224: 18-20.

WHITEHOUSE, K., ZAROW, A. and SHAY, H. 1945. Rapid method for determining 'Crude Fibre' in distillers' dried grain. J. Ass. off. agric. Chern. 28: 147-152.

WOOD-GUSH, D. G. M. 1973. Animal welfare in modern agriculture. Br. ret. J. 119: 167-174. 